\title{
Activities and Accomplishments in Model Year 2007
}

In model year (MY) 2007, covered state and alternative fuel provider (SFP) fleets that report to the U.S. Department of Energy (DOE) complied with Energy Policy Act of 1992 (EPAct) fleet provisions (10 CFR Part 490) by:

- Acquiring 14,851 alternative fuel vehicles (AFVs).

- Earning 3,014 biodiesel credits.

- Purchasing 1,574 AFV credits.

Covered fleets exceeded their MY 2007 requirement by $26 \%$.

This document summarizes Standard Compliance reporting data submitted by covered SFP fleets to DOE for MY 2007. Results published in this report show that fleets continue to meet their EPAct requirements predominantly by using alternative fuel technologies. This document also reports on the waiver applications submitted to DOE for fleets wanting to participate in the Alternative Compliance option for MY 2008. Because MY 2008 Alternative Compliance petroleum reduction goals are still being reached and results are not due to DOE until December 31, 2008, Alternative Compliance activity will be detailed in next year's annual report for the SFP fleet programs.

\section{Status of Covered Fleets}

All 313 entities* covered under the SFP Rule reported to DOE, and, as of July $2008,97 \%$ of them are in compliance. DOE is working with noncomplying fleets to ensure they meet the regulatory requirements.

\section{Alternative Compliance Option}

MY 2007 marked the first opportunity for SFP fleets to submit applications to use the program's new Alternative

* Some entities represent one agency or business; others constitute fleet operations for an entire state.
Compliance option to meet their MY 2008 EPAct requirements. Previously, SFP fleets could only comply with their EPAct requirements through what is now termed "Standard Compliance," which primarily focuses on the acquisition of AFVs. Established by EPAct 2005 and set forth by final rulemaking in March 2007, Alternative Compliance allows fleets to employ petroleum reduction measures in lieu of acquiring AFVs under Standard Compliance.

\section{Standard Compliance}

For the first time in seven years, biodiesel credits decreased in MY 2007, while the number of ethanolcapable flexible fuel vehicles (FFVs) purchased increased. State fleets acquired 13,082 FFVs and alternative fuel providers acquired 826. Additionally, the use of AFV credits to satisfy regulatory requirements reached an all-time high of 1,574 - up from 933 in MY 2006.

For MY 2007 Standard Compliance reporting highlights, see Table 1.

As Table 1 shows, the credits fleets actively earned by acquiring AFVs $(14,851)$ and using biodiesel $(3,014)$ total 17,865 . With all fleets in compliance, the total number of credits required would have been 16,299. Thus, fleet totals exceeded the net credit requirement by about $10 \%$.

\section{Table 1. MY 2007 Highlights}

\begin{tabular}{|l|r|}
\hline AFVs Purchased & 14,851 \\
\hline Total Banked Credits Used & 2,592 \\
\hline Banked Credits Purchased & 1,574 \\
\hline Biodiesel (B100) Used & 4.5 million gallons \\
\hline Biodiesel Credits Awarded & 3,014 \\
\hline
\end{tabular}


Some fleets purchased or used their own banked credits $(2,592)$ to comply. Including these credits in the total of earned credits $(17,865+2,592)$ results in fleets having gone beyond compliance in meeting fleet acquisition requirements by approximately $26 \%$.

\section{Vehicle Acquisitions}

AFV acquisition is the predominant method of Standard Compliance. Under Standard Compliance, 75\% of new, covered LDVs that state fleets acquire must be AFVs, while $90 \%$ of new, covered LDVs alternative fuel providers acquire must be AFVs. AFV acquisition requirements are determined by multiplying a fleet's number of newly acquired, non-excluded LDVs by the applicable percentages. In MY 2007, the number of covered fleet LDV acquisitions was 21,992 , a nearly $12 \%$ increase from the previous year.

To meet this AFV acquisition requirement, covered SFP fleets acquired a total of 14,851 AFVs in MY 2007 - a 16\% increase from the previous year. State fleets acquired 13,217 AFVs - the vast majority of them FFVs.

The MY 2007 acquisition requirement for alternative fuel provider fleets was 5,302 AFVs-1,508 more vehicles than MY 2006's requirement of 3,794 AFVs. The actual number of AFVs acquired was 1,634. As in previous years, fuel providers met their AFV acquisition requirement primarily through the use of banked credits and biodiesel. For the number of MY 2007 AFV acquisitions by covered fleets, see Figure 1. For the breakdown of the types of AFVs covered fleets purchased in MY 2007, see Table 2.

\section{Credit Use and Purchase}

Covered fleets earn bankable credits by acquiring more AFVs than required. They may then use these credits to satisfy future AFV acquisition requirements or sell them to fleets that have acquired an insufficient number of AFVs. In MY 2007, fleets exceeded their AFV requirements and earned 4,158 credits. In MY 2007, fleets used 2,592 banked credits to comply with EPAct-a 10\% increase from MY 2006.

Thirty-nine fleets purchased banked credits from other fleets to help them offset their AFV acquisition requirements. In all, fleets purchased 1,574 credits in MY 2007 compared to 933 in MY 2006-up 68\%. Figure 2 shows this increase in credit purchasing.

\section{Table 2. AFVs Acquired in MY 2006}

\begin{tabular}{|l|c|}
\hline Light-Duty Sedans & 5,418 \\
\hline Light-Duty Pickups & 5,014 \\
\hline Minivans & 2,448 \\
\hline Sport Utility Vehicles & 1,303 \\
\hline Full-Sized Vans & 137 \\
\hline Medium-Duty Trucks & 417 \\
\hline Heavy-Duty Trucks & 33 \\
\hline Buses & 6 \\
\hline
\end{tabular}

Figure 1.

Number of AFVs Acquired in MY 2007

(by Covered Fleets)

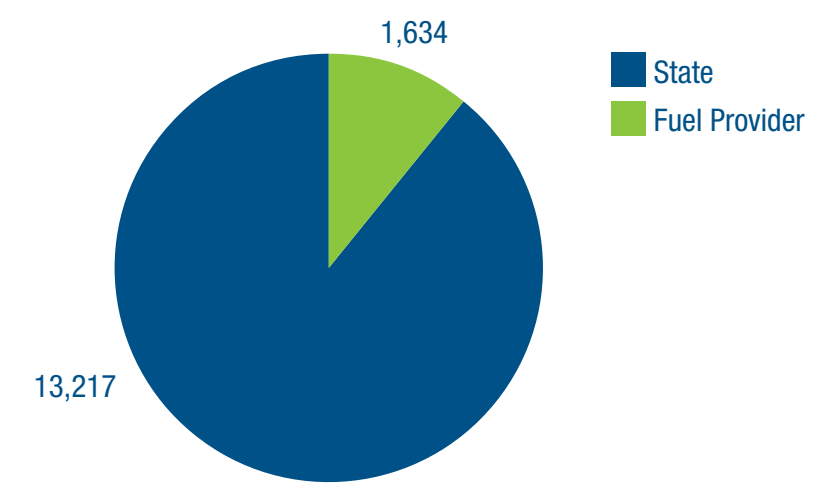

Figure 2.

Credits Purchased Annually

(by Model Year)

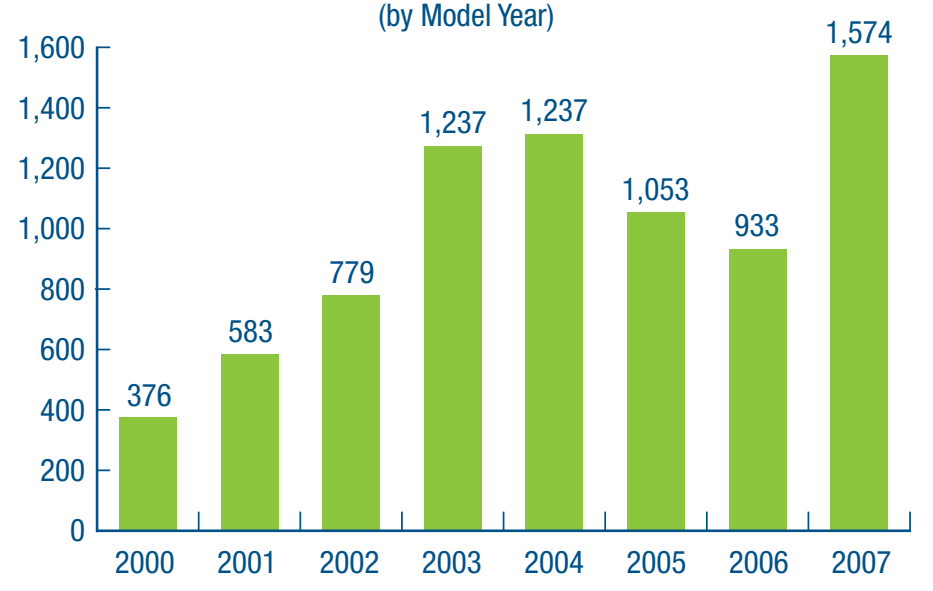




\section{Fleet Fuel Preferences}

In MY 2007, FFVs that run on E85 accounted for $93.6 \%$ of newly acquired AFVs. Vehicles powered by compressed natural gas (CNG) and liquefied natural gas came in second at $4.8 \%$. Liquefied petroleum gas (LPG) and electric vehicles made up the remaining $1.6 \%$. The types of vehicles acquired in MY 2007 were similar to last year with only a minimal shift from FFVs to gaseous fuel vehicles.

Of the 13,908 FFVs acquired in MY 2007, state fleets purchased 13,082. Although EPAct does not require states to use alternative fuels in their AFVs, additional SFP fleets are using E85 and installing onsite fueling infrastructure in response to local mandates requiring them to use E85 and other alternative fuels in state vehicles. According to D0E's Alternative Fuels and Advanced Vehicles Data Center, the total number of E85 fueling sites in the United States is 1,457 stations, ${ }^{*}$ up $26 \%$ since 2006.

Alternative fuel provider fleets also purchased a greater number of E85 FFVs than in MY 2006. These fleets purchased 826 vehicles, up from 526 in MY 2006. DOE expects this trend to continue due to limited AFV models that operate on propane or natural gas and an increasing number of available E85 refueling stations.

${ }^{*}$ As of June 2008.

Figure 3.

AFVs Acquired by Covered Fleets

(by Fuel Type)

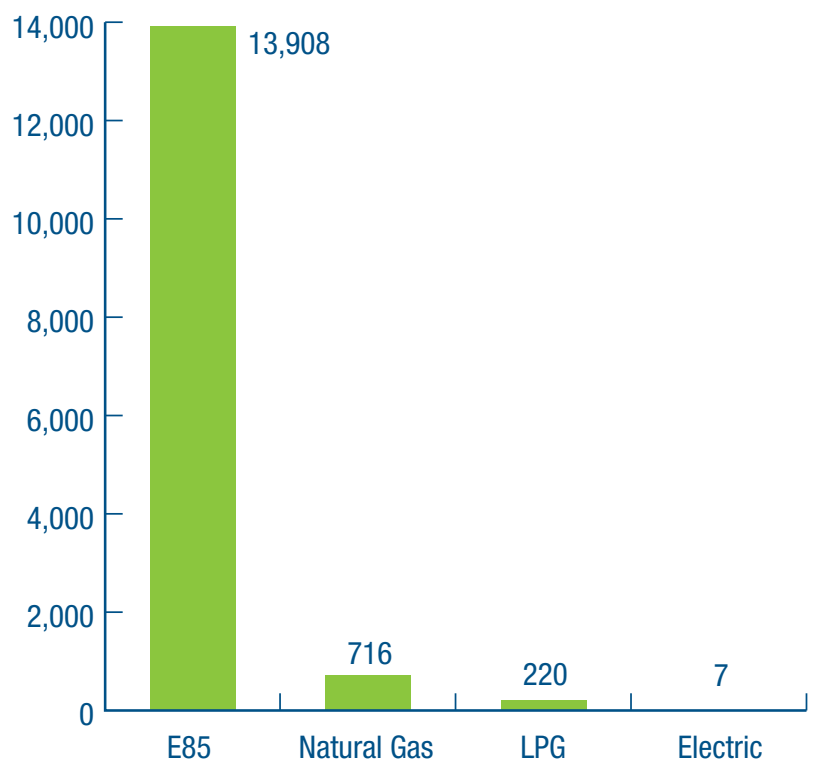

Figure 4. Annual Biodiesel Fuel Use

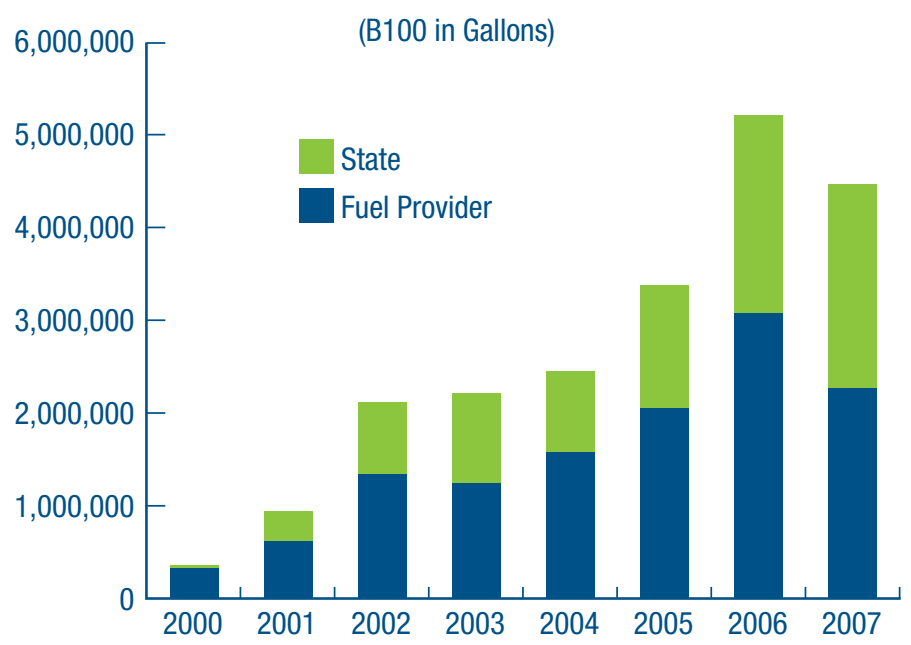

Biodiesel Fuel Credits

Fleets may earn one credit for each 450 gallons of pure biodiesel (B100) or one credit for every 2,250 gallons of B20 (see 10 CFR 490.701-702) they purchase and use. In MY 2007, covered fleets used approximately 4.5 million gallons of B100 in B20 blends, down 20\% from 5.2 million gallons in MY 2006. For the first time since 2000, biodiesel fuel credits decreased, with covered fleets earning a total of 3,014 biodiesel credits. The credits awarded do not necessarily reflect the total amount purchased because each fleet may only apply its biodiesel credits to meet $50 \%$ of its annual requirement.

Also in MY 2007, the number of fleets that used biodiesel increased from 98 to 110 , or $35 \%$ of all covered fleets. Forty state fleets reported using 2.1 million gallons of biodiesel (B100) in MY 2006, while 70 fuel provider fleets used 2.4 million gallons of B100. Although Figure 4 shows fuel providers to be the predominant users of biodiesel, state fleet use of biodiesel also continues to increase-almost doubling since 2005.

\section{Exemptions}

Overall, exemptions* represented a small percentage of fleet activity in MY 2007. Fleets received 1,096 vehicle exemptions - a decrease of 13\% from the 1,268 exemptions granted in MY 2006.

* Exemptions are detailed in the addendum to "Documentation Requirements for Exemption Requests", which is available on the EPAct Web site at www.eere.energy.gov/vehiclesandfuels/epact/pdfs/ exemption_addendum2.pdf. 


\section{Alternative Compliance}

As previously mentioned, MY 2007 was the first year fleets could apply to participate in the Alternative Compliance option for MY 2008. Under Alternative Compliance, fleets must obtain a waiver from DOE for the upcoming model year (in this case, MY 2008). To receive a waiver, fleets must start by submitting an intent to apply for a waiver from DOE. Then they must file an official waiver application that includes a plan of how they intend to reduce petroleum consumption.

In MY 2007, DOE approved applications for eight fleets to participate in Alternative Compliance for MY 2008. Their total required fuel reduction for MY 2008 is a little more than 1.2 million gasoline gallon equivalents

\section{What Is EPAct?}

The Energy Policy Act of 1992 (EPAct) was passed by Congress to reduce the nation's dependence on imported petroleum. Provisions of EPAct require certain fleets to purchase AFVs. DOE administers these requirements through its State \& Fuel Provider Rule, Federal Fleet Requirements, and Alternative Fuel Designation Authority.

For more information, visit www.eere.energy.gov/vehiclesandfuels/ epact, or call the Regulatory Information Line at 202-586-9171.
(GGE). Their total planned fuel reduction is almost 1.5 million GGE. These fleets intend to meet their petroleum consumption reduction goals by:

- Using alternative fuels (38\%).

- Using biodiesel blends (52\%).

- Acquiring and using hybrid electric vehicles (10\%).

- Employing fuel economy measures in conventional vehicles (1\%).

The eight fleets are currently working on their Alternative Compliance goals for MY 2008. Alternative Compliance annual reports, which certify an individual fleet's actual petroleum fuel reductions, are due to DOE each year by December 31 .

\section{Conclusion}

In MY 2007, covered fleets successfully complied with their Standard Compliance requirements. Their efforts included acquiring more than 14,850 AFVs and consuming 4.5 million gallons of biodiesel (B100). Nearly all fleets have reported, and the few fleets with compliance deficiencies are resolving them. DOE has maintained its outreach efforts by continuing to communicate with covered fleets and offering compliance assistance.
Sponsored by the U.S. Department of Energy

Energy Efficiency and Renewable Energy

Vehicle Technologies Program

For more information contact:

EERE Information Center 1-877-EERE-INF (1-877-337-3463) www.eere.energy.gov

Prepared by the National Renewable Energy Laboratory (NREL) NREL is a U.S. Department of Energy National Laboratory Operated by Midwest Research Institute $\bullet$ Battelle

\footnotetext{
A Strong Energy Portfolio for a Strong America

Energy efficiency and clean, renewable energy will mean a stronger economy, a cleaner environment, and greater energy independence for America. Working with a wide array of state, community, industry, and university partners, the U.S. Department of Energy's Office of Energy Efficiency and Renewable Energy invests in a diverse portfolio of energy technologies.
}

DOE/GO-102008-2630 • September 2008

Printed with a renewable-source ink on paper containing at least 50\% wastepaper, including $10 \%$ postconsumer waste 